\title{
CONCEPTUAL MODEL FOR ENERGY-EFFICIENCY MANAGEMENT IN STEAM-POWER PLANTS
}

\author{
OGNYAN DINOLOV*1 \\ ${ }^{I}$ Dept. of Electric Power Engineering, Angel Kanchev University of Ruse, Studentska 8, \\ Ruse, 7017, Bulgaria
}

\begin{abstract}
An aggregate algorithmized conceptual model for controlling the energy efficiency in the steam-power plants, with taking into account the deviations in the qualitative characteristics of the used fuel, is proposed and justified. The model is applied for a coal-fired power plant, at two of its stages, through simulations in MATLAB Simulink and analyzing some of the data with the program Statistica. The development creates preconditions to algorithmize (to model) comprehensive energy efficiency measures in the operating plants, and to design and build new systems for monitoring and controlling the auxiliary electric power demand.
\end{abstract}

Keywords: energy efficiency, steam-power plants, energy efficiency measures, modeling

\section{INTRODUCTION}

The energy efficiency (EE) of a given steam-power plant (SPP) is always bound as to the amount of produced energy, and also with the auxiliary consumption. On the other hand, provided the major environmental impacts (particularly when using coal) and the significant power capacity, maintaining a high efficiency of these objects is a topical issue that should find a quick solution.

While the auxiliary-consumption research and evaluation are well represented in existing studies [1-5], the problem with the methodologically-justified and single-level-placed investigation and improvement of the overall EE in SPP is still insufficiently well exposed. In general, the analysis of the developments in this area, the main of which are described in [6-13], shows a lack of comprehensive models and control algorithms for the energy-savings measures with determining the aggregate criteria and requirements for optimization.

The objective of the study is to propose and justify a generalized conceptual model for control of the EE of SPP with a view to minimize the auxiliary power consumption.

\section{MODEL ELABORATION}

The interrelationships between the elements that significantly impact the EE of SPP can be represented by the conceptual diagram shown in Figure 1. The diagram is composed of 6 blocks. Block 1 reflects the produced electricity, blocks 2 and 3 - the modes of the turbo and steam generators in the plant, and block 5 sets qualitative indicators of the burned fuel. Block 4 represents the auxiliary power consumption and is composed of blocks 4.1 and 4.2, which refer to two groups of electric drives (ED). Group 1 includes ED whose operation does not

\footnotetext{
* Corresponding author, email: odinolov@uni-ruse.bg

(C) 2016 Alma Mater Publishing House
} 
depend on the fuel quality indicators, while Group 2 covers those drives whose regimes (electricity consumption), depend on these indicators.
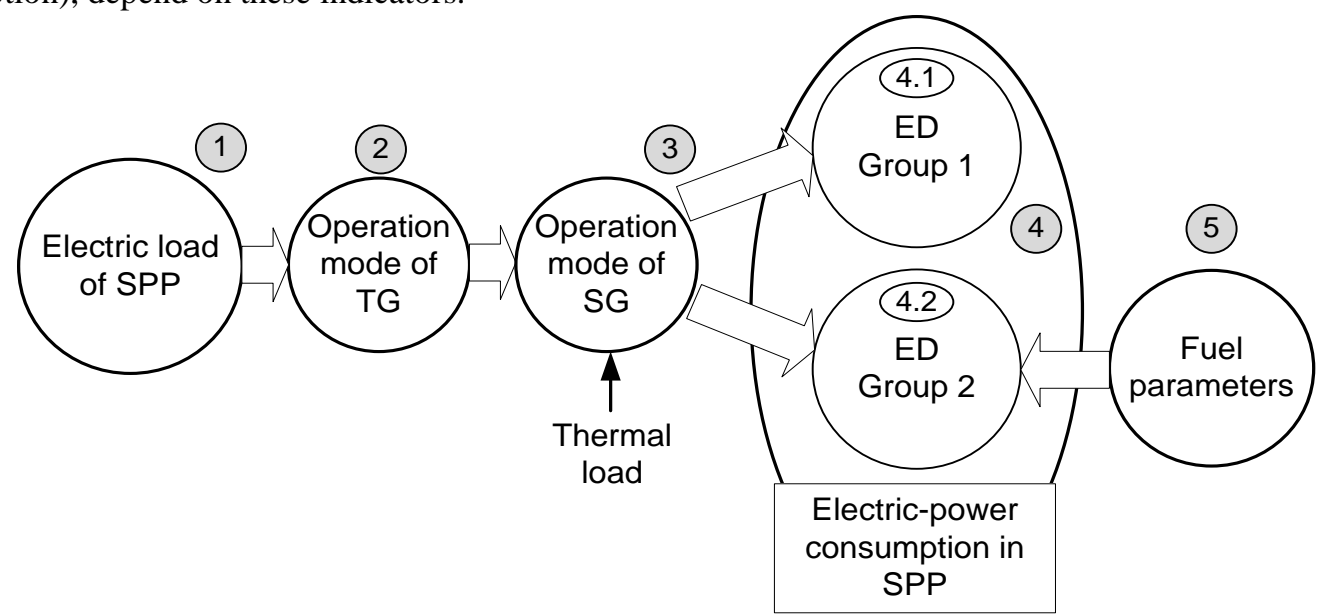

Fig. 1. Conceptual diagram of the interconnections between the elements influencing the energy efficiency of steam-power plants: SPP - steam-power plant; TG - turbo-generator; SG - steam generator; ED - electric drives.

While, as a rule, the SPP load remains constant over time for extended periods [14], the fuel quality parameters vary depending on the source, the lots, the climatic conditions and so on. Therefore, in modeling the EE, it is required the mathematical expected levels of the fuel quality indicators (against which the control criteria to be defined) to be selected as initial conditions. Here, the proven [15] tight relationship between the heat of combustion and the fuel ballast should be taken into account. The relationship suggests that the mathematicallyexpected heat of combustion and the mathematically-expected ballast level will occur simultaneously within the same type and characteristics of fuel (mostly used for the plant).

Considering the above, and taking into account the dominant character of the powerful ED (typically operated at generator voltage), an aggregated target criterion $\boldsymbol{E}^{*}{ }_{a g g, S P P}$ in rel. units for EE control can be proposed which was defined using the relative power consumption $[1,2,15]$ and the mathematically-expected fuel quality parameters:

$$
E_{\text {agg }, S P P}^{*}=\frac{\sum_{i=1}^{i=a} E_{T G, i}^{*}, P_{T G, i}+\sum_{i=1}^{i=b} E_{S G, i}^{*} . P_{S G, i}+\sum_{i=1}^{i=c} E_{E D 1, i}^{*} . P_{E D 1, i}+\sum_{i=1}^{i=d} E_{E D 2, i}^{*} . P_{E D 2, i}}{\sum_{i=1}^{i=a} P_{T G, i}+\sum_{i=1}^{i=b} P_{S G, i}+\sum_{i=1}^{i=c} P_{E D 1, i}+\sum_{i=1}^{i=d} P_{E D 2, i}} \Rightarrow \text { min, } \mid \begin{aligned}
& Q^{r}=\text { const }=\overline{Q^{r}} \\
& B=c o n s t=\bar{B}
\end{aligned}
$$

where $E_{T G, i}^{*}$ and $E_{S G, i}^{*}$ are the relative power consumptions in rel. units of the i-th turbo and steam generator in the plant, respectively, $P_{T G, i}$ and $P_{S G, i}$ are the actual active powers of these generators in $\mathrm{kW}, E_{E D 1, i}^{*}$ and $E_{E D 2, i}^{*}$ are the relative power consumptions in tel. units of the i-th ED in the Groups 1 and 2, operating at generator voltage, $P_{E D 1, i}$ and $P_{E D 2, i}$ are the actual active powers of these drives in $\mathrm{kW}, Q^{r}$ and $\overline{Q^{r}}$ are the actual and the mathematically expected heat of combustion in $\mathrm{kJ} / \mathrm{kg}$, respectively, $\mathrm{B}$ and $\bar{B}$ are the actual and the mathematically expected level of the fuel ballast in \% and a, b, c, d are the number of TG, SG and ED from the Groups 1 and 2, respectively.

In reaching the minimum aggregate relative consumption $E_{a g g, S P P}^{*}$, it should be expected that the auxiliary electricity consumption will be minimal as possible, while at maximum power generation. In order to fulfill this condition, a set of measures need to be taken, which can be modeled and defined in a sequence determined by control algorithms of the type shown in Figure 2. 
Initially, the TG load should be maintained as to correspond to the minimum possible relative consumption of the turbo unit (maximum efficiency). Under these conditions, measures are to be taken so that the specific steam consumption of the SG to be minimal. Once determined, the optimum (in energetics terms) operation of the SG dictates the necessary basis powers $[1,2,15]$ of the ED in order to provide their normal work, eg. physicallydemanded power for pumping the required amount of water in the drum, the power to overcome the gravitational forces, the power to ensure the mass flows etc.

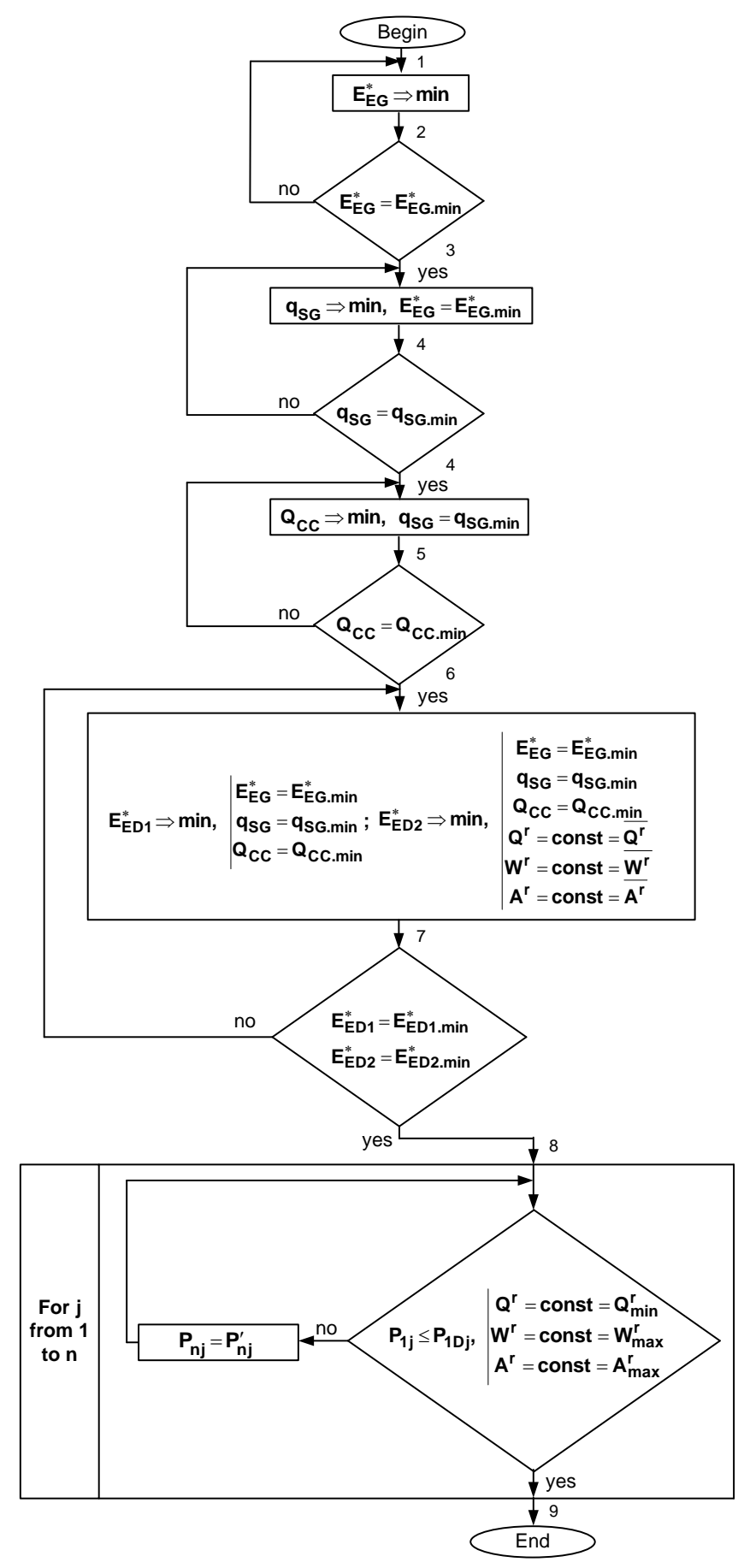

Fig. 2. Algorithmic interpretation of a methodology for managing the energy efficiency measures in a given power block in SPP.

Taking into account the losses in each ED element, the electric motors are selected so that their load falls within the zones of the energy efficient power consumption [16], in which the relative consumption is minimal. For SPP 
with coal as a main primary energy source, a test for overloading the ED in group 2 should be performed in case that the plant operates with the lowest quality coals and under the worst weather conditions (highest ballast). Maintenance of the electric-motors loads within the zone " $b$ " is respected according to the adopted model [16] for determining the energy-efficient operations of the motors. Contemporary regulation methods, such as using frequency converters should be applied in case of changing the ED duties.

The following symbols are used in the algorithmic model of Figure 2: $E_{E G}^{*}$ - relative consumption of the plant's electric generator (determined as a ratio of the shaft power to the active electric power) rel. units; $q_{S G}-$ specific steam productivity of the $\mathrm{SG}, \mathrm{kg} / \mathrm{s} ; Q_{C C}$ - thermal energy emitted into the combustion chamber of the $\mathrm{SG}, \mathrm{kJ} / \mathrm{s}$; $E_{E D 1}^{*}$ - relative electric-power consumption of ED in Group 1, rel. units (determined as a ratio of the sum of the active electric powers to the sum of the basis, entirely useful, powers of the drives); $E_{E D 2}^{*}$ - also, but for Group 2, rel. units; $P_{1 j}$ - active consumed power of the j-th ED from Group 2, kW; $P_{1 D j}$ - active threshold power of zone D in the model [16] for determining the energy-efficient operation modes of the electric motors of the ED in Group 2, $\mathrm{kW} ; P_{n j}$ - the nominal motor power of the j-th ED from Group 2, $\mathrm{kW} ; P_{n j}^{\prime}$ - the nominal power of the next larger frame size motor compared to the motor of the $\mathrm{j}$-th ED on Group $2, \mathrm{~kW} ; E_{E G \text {.min }}^{*}$ - the minimum

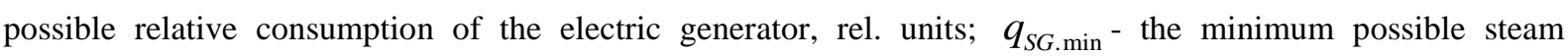
productivity of the $\mathrm{SG}, \mathrm{kg} / \mathrm{s} ; Q_{C C \text {.min }}$ - the minimum possible thermal energy emitted into combustion chamber, $\mathrm{kJ} / \mathrm{s} ; Q_{\min }^{r}$ - the minimum possible heat of combustion, $\mathrm{kJ} / \mathrm{kg} ; W^{r}, W_{\max }^{r}$ and $\overline{W^{r}}$ - the current, the maximum and the mathematically-expected (average) relative moisture content of the fuel, respectively, $\% ; A^{r}, A_{\max }^{r}$ and $\overline{A^{r}}$ - the current, the maximum and the mathematically-expected (average) relative ash content of the fuel, respectively, \%; $\mathrm{n}$ the number of ED in Group 2; $\mathrm{j}$ - the sequence number of the ED in Group 2.

The synthesized model can be adopted as in optimizing the existing SPP and in the re-engineering of these plants, as well in the construction of new SPP.

\section{CASE STUDIES}

In this study, the model is applied for blocks 4 and 5 of the conceptual diagram (Figure 1). Data and an object (coal handling system in a SPP) from a previous research [1] are used. A test for overloading the existing electric motors of the system, while working with the lowest-quality coal, is made. A simulation model in MATLAB Simulink is made (Figure 3) in order to make this test. The input parameters of the model are: output of the conveyors; working duration, nominal motor power; actual electric-motor efficiency and power; height of coal elevation; and minimum and average heat of combustion of coal. The model output value is a logical: $0-$ the motor is not a subject of replacement; 1 - the motor has to be replaced. The used values of the model input parameters are represented by Table 1 , as the obtained results are shown in Table 2.

While testing, the following assumptions were made:

- the algorithm of Figure 2 is realized by point 8, including;

- the losses of the ED mechanisms are constant;

- the presence of regulating masses (intermediate bunkers) in the system is not accounted.

It can be seen from Table 2 that the motor of conveyor 5 will be overloaded at the worst possible quality coal parameters and it should be replaced with a motor with a higher power. 


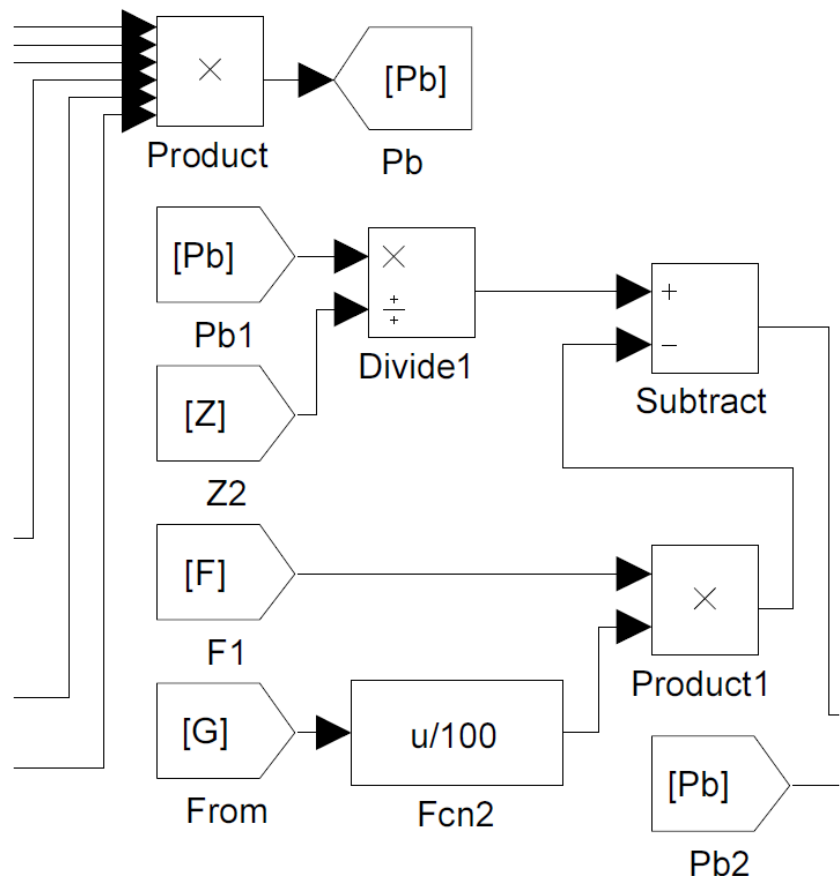

Fig. 3. Fragment of a developed simulation model for testing the nominal power of asynchronous motors in a coal handling system of a SPP.

Table 1. Values of some of the input parameters of a model for testing the nominal power of asynchronous electric motors of belt conveyors

\begin{tabular}{|c|c|c|c|c|c|c|c|}
\hline Conveyor number: & 1 & 2 & 3 & 4 & 5 & 6 & 7 \\
\hline Actual output $\mathrm{A}, \mathrm{t} / \mathrm{h}$ & \multicolumn{7}{|l|}{524.29} \\
\hline Motor efficiency $\eta, \%$ & 91.32 & 93.37 & 92.93 & 89.77 & 91.73 & 92.25 & 86.29 \\
\hline Out-of-leveling h, m & 2.5 & 2 & 32.7 & 22.5 & 0 & 2 & 0 \\
\hline Consumed electric power $\mathrm{P}_{1}, \mathrm{~kW}$ & 33.82 & 72.57 & 84.60 & 32.50 & 36.71 & 23.94 & 16.73 \\
\hline Working duration $\mathrm{t}$, min & 76 & 74 & 75 & 79 & 79 & 35 & 35 \\
\hline Nominal motor power $\mathrm{P}_{\mathrm{n}}, \mathrm{kW}$ & 75 & 110 & 160 & 75 & 30 & 30 & 55 \\
\hline
\end{tabular}

Table 2. Results of the testing the nominal power of asynchronous electric motors of a coal handling system in a

\begin{tabular}{|l|l|l|l|l|l|l|l|}
\hline Conveyor number: & 1 & 2 & 3 & 4 & 5 & 6 & 7 \\
\hline Type of the existing motor & $\begin{array}{l}\text { AO2- } \\
92-6\end{array}$ & $\begin{array}{l}\text { AO315- } \\
\text { S6 }\end{array}$ & $\begin{array}{l}\text { M- } \\
280 \text {-6 } 6\end{array}$ & $\begin{array}{l}\text { MO- } \\
280 \text { S-6 }\end{array}$ & $\begin{array}{l}\text { AO2- } \\
81-6\end{array}$ & $\begin{array}{l}\text { AO2- } \\
81-6\end{array}$ & $\begin{array}{l}\text { MO250- } \\
\text { M6 }\end{array}$ \\
\hline $\begin{array}{l}\text { Nominal power of the existing } \\
\text { motor, kW }\end{array}$ & 75 & 110 & 160 & 75 & 30 & 30 & 55 \\
\hline $\begin{array}{l}\text { Nominal power of the } \\
\text { replacing motor, kW }\end{array}$ & - & - & - & - & 45 & - & - \\
\hline
\end{tabular}

In the present work, a study on the quality parameters of the coal used in the SPP has been made in order to justify the applicability of the approach related to selecting and setting the electric-drives operating modes respecting the average ballast levels of the used fuel. Three quality parameters are examined - the heat of combustion $\mathrm{Q}^{\mathrm{r}}$, the moisture content $\mathrm{W}^{\mathrm{r}}$ and the ash content $\mathrm{A}^{\mathrm{r}}$. Forty-four fuel samples are analyzed by using the software Statistica. It was found that the parameters' values are grouped around the center (Figure 4). 


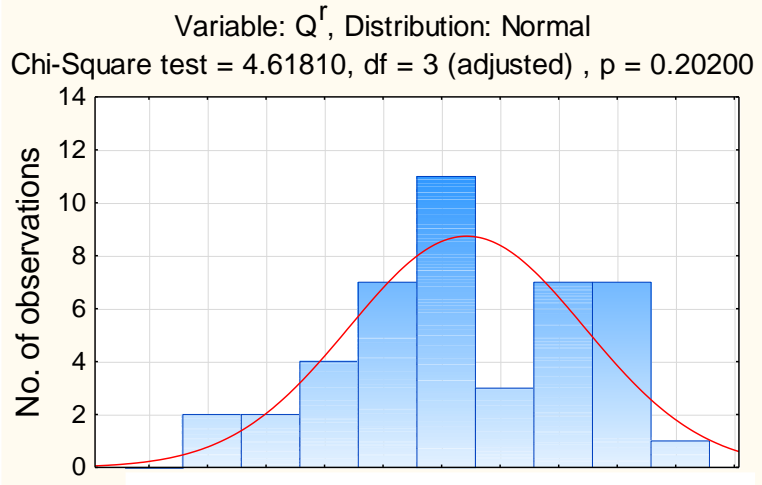

a)
Variable: $\mathrm{W}^{\mathrm{r}}$, Distribution: Normal Chi-Square test $=1.74811, \mathrm{df}=1$ (adjusted), $\mathrm{p}=0.18611$

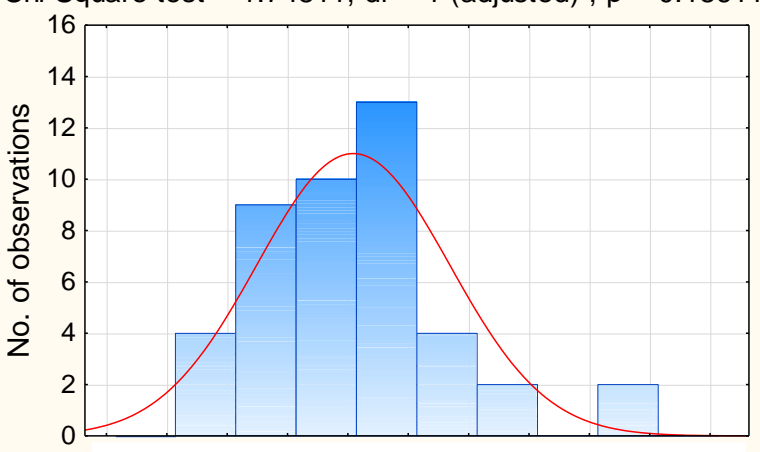

b)

Variable: $A^{r}$, Distribution: Normal

Chi-Square test $=0.79009, \mathrm{df}=1$ (adjusted), $\mathrm{p}=0.37407$

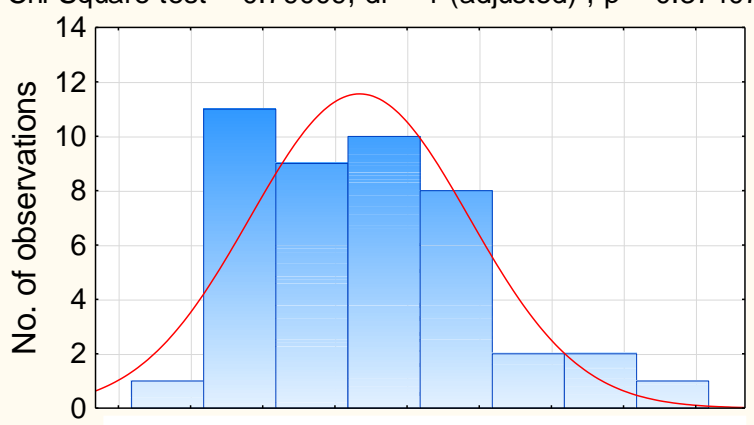

c)

Fig. 4. Results for the distribution of the heat of combustion $\mathrm{Qr}(\mathrm{a})$, the moisture content $\mathrm{Wr}(\mathrm{b})$ and the ash content $\operatorname{Ar}(\mathrm{c})$ of the coal

The distribution is assessed as normal since the null hypothesis cannot be rejected. This is established from the executed Chi-Square test. The resulting values for the Chi-Square test parameter $\chi^{2}$ are below the limit values which, given the obtained degrees of freedom and probabilities (see Figure 4), are 5.280, 2.143 and 1.017 for $\mathrm{Q}^{\mathrm{r}}$, $\mathrm{W}^{\mathrm{r}}$ and $\mathrm{A}^{\mathrm{r}}$, respectively. This shows that, for the particular plant, the mathematical expectation of the fuel ballast and of the heat of combustion should be evaluated by the arithmetic average.

\section{CONCLUSIONS}

Based on the relative energy consumption, a target criterion is defined that sets the conditions for achieving a maximum EE in SPPs while considering the variations in the quality characteristics of the used fuels.

A complete algorithmic methodology for organization and management of the energy-efficiency measures is developed which is a starting condition for achieving a minimum aggregate relative consumption in SPPs.

The justified applicability for blocks 4 and 5 (Figure 1) and the obtained results give reasons to expect possibilities for potential application of the model as a whole. The workability of blocks 1,2 and 3 of the model should be a subject of further research.

The work is creating preconditions for:

- Modeling the energy-efficient operations of SPPs towards the variations in the fuel quality indicators and in the aggregate relative consumption of electrical, thermal and mechanical energy. 
- Designing and implementing qualitatively new and informative systems for monitoring and control of the electric-energy efficiency of SPPs, regardless of the type of the primary energy carrier.

\section{REFERENCES}

[1] Andonov, K., Dinolov, O., Kirchev, V., Nedev, G., Energy-efficiency investigation of a coal-feeding system, Energetika, Bulgaria, no. 8, 2007, p. 26 - 33.

[2] Andonov, K., Dinolov, O., Koev, K., Nedev, G., Kirchev, V., Studying the energy efficiency of a flue gas system in a coal-fired power plant, Energetika, Bulgaria, no. 6-7, 2009, p. 40 - 45.

[3] Chen, G., Technico-economic argumentation of a feedwater pump drive-mode based on an energy value analysis, Reneng Dongli Gongcheng/Journal of Engineering for Thermal Energy and Power, vol. 18, no. 1, 2003, p. $97-100+111$.

[4] Wang, S., Ye, J., Li, W., Du, X., Chen, Z., Energy efficiency evaluation investigation on high voltage inverter retrofit for fans and pumps in power plants, 44th International Conference on Large High Voltage Electric Systems 2012, Paris, France, 26 - 31 August 2012.

[5] Dinolov, O., Nedev, G., Kirchev, V., Andonov, K., Studying the energy efficiency of a coal preparation system with an intermediate bunker, Proceedings of the University of Ruse, vol. 46, series 3.1, 2007, p. $16-22$.

[6] Fonseca Jr., J., Schneider, P., Simulation of a thermal power plant with district heating: Comparative results of 5 different codes, Energy, vol. 31, no. 12, 2006, p. 1955 - 1968.

[7] He, B., Chen, C., Energy ecological efficiency of coal fired plant in China, Energy Conversion and Management, vol. 43, no. 18, 2002, p. 2553 - 2567.

[8] Ma, W., Chen, Y., Yao, D., PC-based real-time simulator and its application on testing of power plant auxiliary system control, 2010 International Conference on Power System Technology: Technological Innovations Making Power Grid Smarter POWERCON2010, Hangzhou, China, 24 - 28 October 2010.

[9] Mandi, R., Yaragatti, U., Energy efficiency improvement of auxiliary power equipment in thermal power plant through operational optimization, IEEE International Conference on Power Electronics, Drives and Energy Systems, Bengaluru, Karnataka, India, 16 - 19 December 2012.

[10] Sarica, K., Or, I., Efficiency assessment of Turkish power plants using data envelopment analysis, Energy, vol. 32, no. 8, 2007, p. 1484 - 1499.

[11] Weed, G., Improve power plant operations by empowering operators, American Society of Mechanical Engineers, Power Division (Publication) PWR, vol. 17, 1992, p. 7-16.

[12] Yang, Y., Shi, Q., Jin, R., Zhai, S., Analysis of the thermal cost-effectiveness of the exhaust steam of the steam-driven induced draft fan of a utility boiler when introduced into deaerators, Reneng Dongli Gongcheng/Journal of Engineering for Thermal Energy and Power, vol. 28, no. 3, 2013, p. 301-306.

[13] Zhao, Z., Zhang, Q., Wang, J., The diagnosis and optimal adjustment of combustion on a 2000t/h boiler, Asia-Pacific Power and Energy Engineering Conference, APPEEC, Shanghai, China, 27 - 29 March 2012.

[14] Batey, J., Steam Boilers and Combustion, vol. XV, BiblioBazaar, 2008, p. 220.

[15] ,inolov, O., Modeling the energy-efficient operations of induction motors, Electrotehnica \& Electronica E+E, Bulgaria, 2010, vol. 3-4, p. 26-29. 